\title{
Interleukin-13 Increases Podocyte Apoptosis in Cultured Human Podocytes
}

\author{
Keum Hwa Lee, M.D. ${ }^{1,2}$ \\ JiYoung Oh, M.D. ${ }^{1}$ \\ Su-Bin Seong, M.D. ${ }^{3}$ \\ Tae-Sun Ha, M.D., Ph.D. ${ }^{3 *}$ \\ Jae Il Shin, M.D., Ph.D. ${ }^{1,2,4 *}$ \\ 'Department of Pediatrics, Yonsei \\ University College of Medicine, Seoul, \\ Korea, ${ }^{2}$ Department of Pediatric \\ Nephrology, Severance Children's Hospital, \\ Seoul, Korea, ${ }^{3}$ Department of Pediatrics, \\ Chungbuk National University College of \\ Medicine, Cheongju, Korea, ${ }^{4}$ Institute of \\ Kidney Disease Research, Yonsei University \\ College of Medicine, Seoul, Korea
}

*These authors are co-correspondence to this work.

Corresponding author 1: Tae Sun Ha, M.D., Ph.D. Department of Pediatrics, Chungbuk National University College of Medicine, 410 Sung Bong-Ro, Heungduk-gu, Cheongju 28644, Korea

Tel: +82-43-269-6374, Fax: +82-43-264-6620

E-mail: tsha@chungbuk.ac.kr

Corresponding author 2: Jae II, Shin, M.D., Ph.D. Department of Pediatrics, Yonsei University

College of Medicine, Seoul50 Yonsei-Ro, Seodaemun-gu, Seoul 03722, Korea Tel: +82-2-2228-2050, Fax: +82-2-393-9118

E-mail:shinji@yuhs.ac

Received: 28 March 2018

Revised: 3 April 2018

Accepted: 3 April 2018

This is an open-access article distributed under the terms of the Creative Commons Attribution Non-Commercial License (http:// creativecommons.org/licenses/by-nc/4.0/) which permits unrestricted non-commercial use, distribution, and reproduction in any medium, provided the original work is properly cited.
Purpose: Podocytes are important architectures that maintain the crucial roles of glomerular filtration barrier functions. Despite this structural importance, however, the mechanisms of the changes in podocytes that can be an important pathogenesis of minimal change nephrotic syndrome (MCNS) are not clear yet. The aim of this study was to investigate whether apoptosis is induced by interleukin (IL)-13 in cultured human podocytes.

Methods: Human podocytes were treated with different IL-13 doses and apoptotic cells were analyzed using terminal deoxynucleotidyl transferase dUTP nick-end labeling (TUNEL assay) and fluorescence-activated cell sorting (FACS).

Results: The IL-13 increased the number of TUNEL-positive cells in a dose-dependent manner at 6 and 18 hours ( $P<0.05$ and $P<0.05$, respectively). The apoptosis rate was appeared to be increased slightly in the IL-13-stimulated podocytes ( 8.63 $\%, 13.02 \%$, and $14.46 \% ; 3,10$ and $30 \mathrm{ng} / \mathrm{mL}$, respectively) than in the control cells (7.66\%) at 12 hours by FACS assay.

Conclusion: Our study revealed that IL-13 expression may increase podocyte apoptosis. Blocking the IL-13 signal pathway can potentially play an important role in regulating the apoptosis of podocytes.

Key words: Interleukin (IL)-13, Podocytes, Apoptosis, Minimal change nephrotic syndrome (MCNS)

\section{Introduction}

Minimal change nephrotic syndrome (MCNS) accounts for $84.5 \%$ of idiopathic nephrotic syndrome (INS) in children, and 10 to $25 \%$ of INS in adults ${ }^{1,}$ 2). About $80-90 \%$ of children with childhood INS are steroid-sensitive nephrotic syndrome (SSRS) and around $60 \%$ of MCNS children show SSRS ${ }^{3,4}$. Even though initial response rate to steroids is $90 \%$ to $95 \%, 20-60 \%$ of SSRS children relapse and about $60-90 \%$ of them will have five or more relapses with increased morbidity ${ }^{4,5)}$. Resistance to therapy, also called as steroid-resistant nephrotic syndrome (SRNS), occurs in 50\% of focal segmental glomerulosclerosis (FSGS) and 10\% of MCNS often progress to renal failure requiring dialysis and transplantation despite various immunosuppressive treatments $^{6-9)}$.

MCNS is composed of two important pathologic features: 1) absence of glomerular immune complex deposition and 2) foot process effacement (podocytes seem to be fused together a flattened morphology $)^{8)}$. Foot process 
effacement is closely related the changes in the selective barrier in the slit diaphragm, which is composed of a number of proteins: nephrin, P-cadherin, CD2-associated protein, zona occludens (ZO)-1, Fat cadherin, podocin, and Neph1 $1^{10,11)}$.

Interleukin (IL)-13 is a kind of T cell-derived cytokine ${ }^{12}$. It is also reported to be an important cytokine in MCNS and we previously reported that IL-13 may increase podocyte permeability through the modulation of $\mathrm{ZO}-1^{13,14)}$. However, there have been no reports about podocyte apoptosis related to IL-13. The aim of this study was to investigate whether apoptosis is induced by IL-13 in cultured human podocytes.

\section{Materials and methods}

\section{Cell culture of human podocytes}

Human conditionally immortalized podocytes (AB8/23) was cloned from human glomerular cultures. Dr. Moin A. Saleem (University of Bristol, Bristol, UK) characterized and generously provided them. Then human podocytes were maintained in RPMI 1640 (WelGENE Inc., Daegu, South Korea) supplemented with $10 \%$ heat-inactivated fetal bovine serum (FBS), Insulin-Transferrin-SeleniumPyruvate Supplement (ITSP; WelGENE Inc.), and antibiotics. Once every 2 days, fresh media was supplied.

Cells were cultivated at $33^{\circ} \mathrm{C}$ (permissive conditions) in a culture medium supplemented with human recombinant ITSP to induce expression of temperature-sensitive large T antigens and to stimulate human podocyte proliferation. To induce differentiation, podocytes were maintained at $37^{\circ} \mathrm{C}$ (non-permissive conditions) for at least 2 weeks, and for subcultures, $0.05 \%$ trypsin was used to detach cells from the culture dishes.

\section{IL-13 treatment conditions}

To imitate MCNS-like conditions, cells were incubated with various concentrations of IL-13 (Peprotech Inc., Rocky Hill, NJ, USA) during the indicated time periods $(6,12$ and 18 hours). IL-13 was administered with various concentrations $(3,10,30$, and $100 \mathrm{ng} / \mathrm{mL})$ into $0.5 \% \mathrm{RPMI}$ at $37^{\circ} \mathrm{C}$.

\section{Measurement of apoptosis}

1) Terminal deoxynucleotidyl transferase dUTP nickend labeling (TUNEL assay)

TUNEL assay was done using In situ Cell Death Detection Kit (Roche Molecular Biochemicals, Mannheim, Germany). Podocytes that were grown on type I collagencoated glass coverslips incubated for 24 hours were fixed in $4 \%$ paraformaldehyde for 1 hour, followed by permeabilization with $0.1 \%$ Triton X-100 for 10 minutes at room temperature. After coverslips were mounted in mountant, the samples were immediately evaluated using a fluorescence microscope. The TUNEL index (apoptotic podocytes) was determined by counting the positively and negatively stained cells in each of 10 fields of vision. Cell numbers were converted to percent apoptotic cells for statistical analysis.

\section{2) Fluorescence-activated cell sorting (FACS)}

We conducted a flow cytometric analysis to elucidate whether IL-13 has apoptotic effects on podocytes. The apoptotic rate was calculated by a single-color flow cytometric analysis depending upon the IL-13 concentrations (control, 3, 10, and $30 \mathrm{ng} / \mathrm{mL}$ ) and apoptotic hours (6 and 12 hours). Equal numbers of podocytes were cultivated on $6 \mathrm{~cm}$ tissue culture plates in medium. After IL-13 modulation, cell culture medium was collected and saved. Cells were washed once with $1.5 \mathrm{ml}$ of phosphate-buffered saline (PBS). PBS used for washing was combined with the saved culture medium. Podocyte cells were analyzed with the Mofro Astrios flow cytometer (FACSCalibur-S System, Becton Dickinson Biosciences, San Jose, CA, USA). The number of apoptotic cells was calculated by multiplying the percentages of apoptosis and necrosis as determined by FACS.

\section{Statistical analysis}

Results are described as mean \pm standard deviation, as appropriate under different conditions. Statistical significance was evaluated by the non-parametric Kruskal-Wallis analysis or Student's t-test. $P$-values $<0.05$ were considered significant. 


\section{Results}

\section{Apoptotic rate on TUNEL assay}

Apoptosis is a programmed cell death which results the series of events including alterations in the plasma membrane, activation of enzymes ${ }^{15}$. DNA fragmentation can be detected in terminal stages of apoptosis by labeling with fluorescent tagged nucleotides through a technique called as TUNEL ${ }^{16)}$. Apoptotic podocytes were identified as TUNEL positive cells while the normal cells lacked nuclear staining. IL-13 increased the number of TUNEL-positive cells in a dose-dependent manner at 6 and 18 hours $(P<0.05$ and $P<0.05$, respectively) (Fig. 1,2).

\section{FACS assay for apoptosis}

The apoptotic effects of IL-13 on podocytes were analyzed by FACS. There was no significant difference in the rate of apoptosis in controls and podocytes stimulated by different concentrations $(3,10$ and $30 \mathrm{ng} / \mathrm{mL})$ at 6 hours (9.73\% vs. $13.89 \%, 12.52 \%, 10.83 \%$, respectively, Fig. 3 ); at 12 hours, however, the rate of apoptosis was slightly increased in IL-13 stimulated podocytes $(8.63 \%, 13.02 \%$, $14.46 \%$ ) than control cells (7.66\%, Fig. 4).

\section{Discussion}

Podocytes are important structures which maintain the crucial roles of glomerular filtration barrier functions ${ }^{9,10)}$. In 2007, Lai et al. suggested that IL-13 overexpression could lead to podocyte injury with downregulation of proteins such as nephrin, podocin, and dystroglycan and a concurrent upregulation of B7-1 in MCNS induced rat $^{17)}$. After that, our previous studies reported that IL-13 was involved in the changes of ZO-1 proteins in podocytes which could

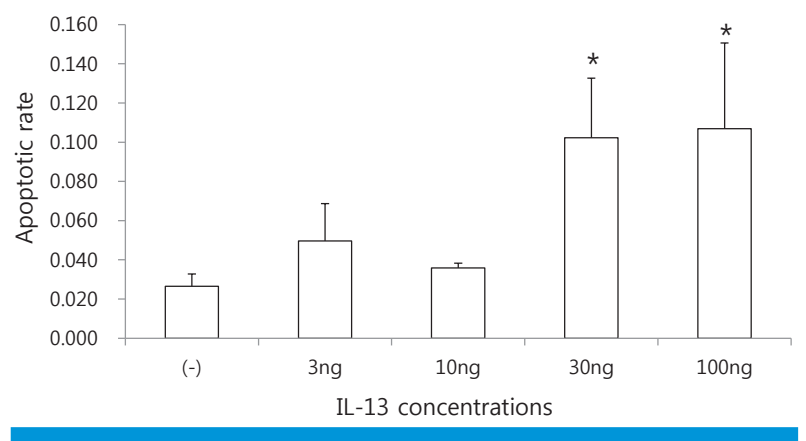

Fig. 1. TUNEL assay for apoptosis (6 hours). IL-13 increased the number of TUNEL-positive cell in a dose-dependent manner at 6 hours $\left({ }^{*} P<0.05\right)$. IL-13, interleukin-13; TUNEL, terminal deoxynucleotidy 1 transferase dUTP nickend labeling.

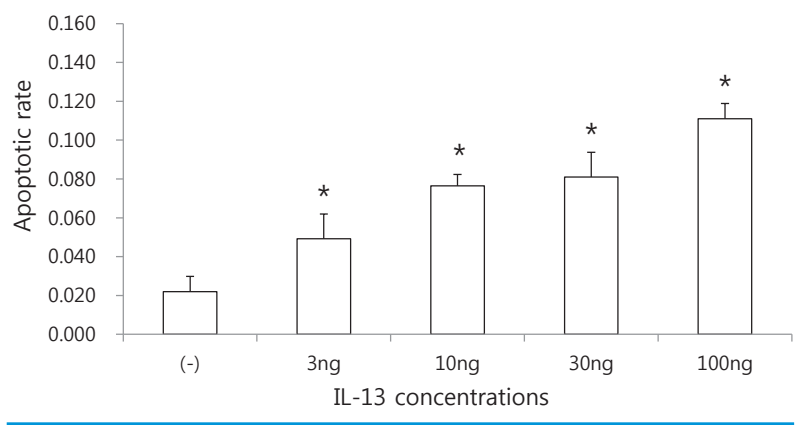

Fig. 2. TUNEL assay for apoptosis (18 hours). IL-13 increased the number of TUNEL-positive cell in a dose-dependent manner at 18 hours $\left({ }^{*} P<0.05\right)$. IL- 13 , interleukin-13; TUNEL, terminal deoxynucleotidy 1 transferase dUTP nickend labeling.
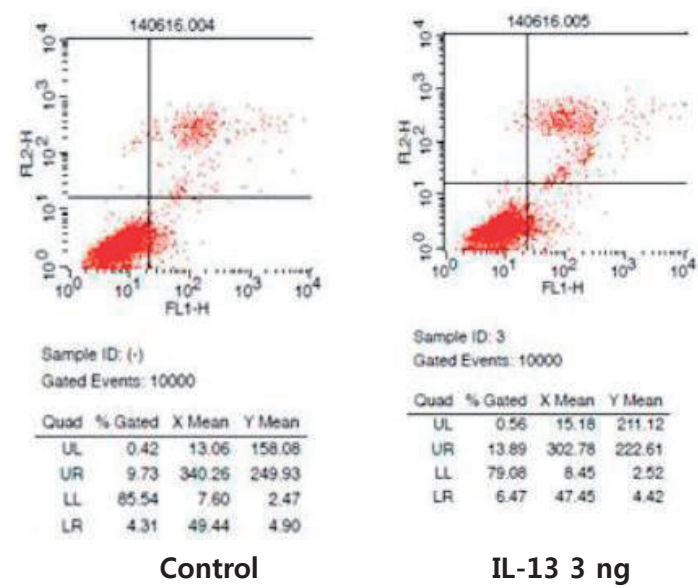

Sample ID: 3 Gared Evenas. 10000 Ousd 5 Gated X Mean YMlean $\begin{array}{cccc}\text { UL. } & 0.56 & 15.18 & 211.12\end{array}$ $\begin{array}{llll}\text { UR } & 1389 & 30278 & 226.61\end{array}$ \begin{tabular}{rrrr}
$L$ & 79.06 & 8.45 & 2.52 \\
\hline L & 6.47 & 47.45 & 4.42
\end{tabular}

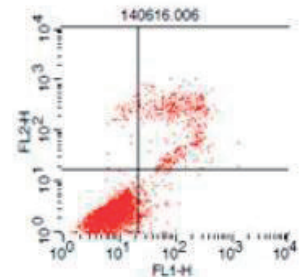

Sample ID: 10

Gared Events: 10000

Ousd 5 Goced X Mean YMean

$\frac{\text { Ousd 5 Gowed X Mean YMean }}{\text { UL } \quad 1.41 \quad 1402}$

$\begin{array}{rrrrr}\text { UL } & 1.41 & 14.02 & 342.07 \\ \text { UR } & 12.52 & 161.04 & 224.42\end{array}$

$\begin{array}{lrrr}\text { LL } & 82.82 & 8.18 & 2.45 \\ \text { LA } & 3.25 & 42.68 & 5.34\end{array}$

IL-13 $10 \mathrm{ng}$

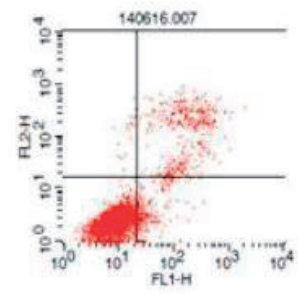

Sancie 10: 30

Gasod Events: 10000

Ousd soased XMean Y Mean

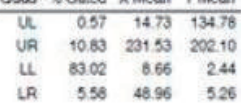

IR $\quad 558 \quad 4895 \quad 528$

IL-13 30 ng

Fig. 3. FACS assay for apoptosis (6 hours). FACS, fluorescence-activated cell sorting; IL-13, interleukin-13. 

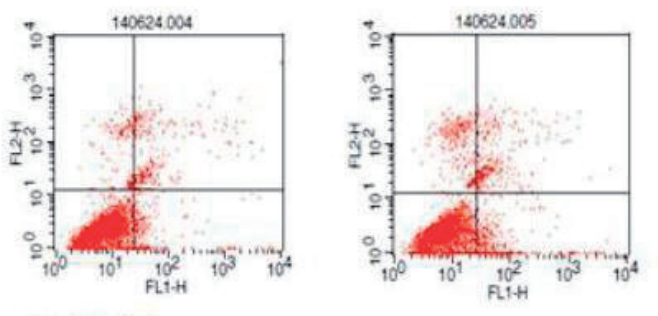

Sample 1D: CONT Gated Events: 10000 Ouad 5 Gated X Mean YMean UL $4.42 \quad 15 \% 9 \quad 12976$ $\begin{array}{llll}\text { UR } & 766 & 26839 & 12589\end{array}$ \begin{tabular}{rrrr}
$u$ & 83.21 & 8.13 & 2.48 \\
\hline L & 471 & 35899 & 272
\end{tabular}

Control

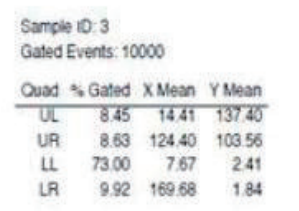

IL-13 3 ng

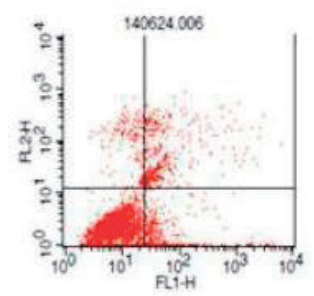

Samole 10: 10 Gated Events: 10000

Ouad so Gated XMean Y Meen UL $5.42 \quad 16.67138 .94$

UA $1302 \quad 140.68 \quad 10283$

$\begin{array}{rrrr}\text { U. } & 70.01 & 8.56 & 2.42 \\ \text { LA } & 11.55 & 182.47 & 205\end{array}$

IL-13 10 ng
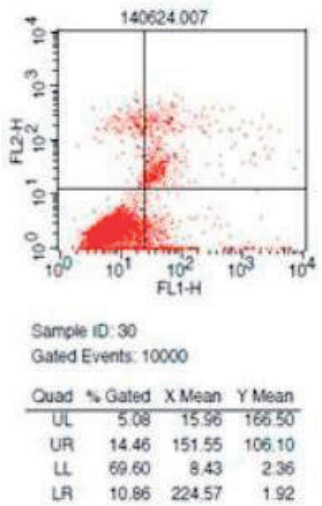

IL-13 $30 \mathrm{ng}$

Fig. 4. FACS assay for apoptosis (12 hours). FACS, fluorescence-activated cell sorting; IL-13, interleukin-13.

be a pathogenesis of $\mathrm{MCNS}^{14,18)}$. Other recent studies have shown that increase in IL-13 production was to cause frequent relapse in $\mathrm{SSNS}^{13,19)}$. In this point of view, the aim of this study was to identify whether apoptosis in podocytes could be induced by IL-13.

There have been two suspected modes of podocyte apoptosis: 1) intrinsic apoptosis and 2) extrinsic apoptosis. Intrinsic apoptosis is related to a mitochondrion-centered control mechanism ${ }^{20)}$. On the other hand, extrinsic apoptosis is a caspase-dependent cell death related to activation of the caspase-9-caspase- 3 cascade $^{21,22)}$. Generally, caspase3 is known as a key mediator as a leading enzyme in cell death $^{23}$. Pro-caspase-3 is usually processed by autoproteolytic cleavage and activated caspase- 3 has been identified that are related to mitochondrial cytochrome c release and caspase-9 function ${ }^{24,25)}$. Manna et al. reported that IL-13 is a potent inhibitor of TNF-mediated activation and caspase3 related apoptosis in $1998^{26)}$. In contrast, recent studies show IL-13 induces apoptotic pathways of cell death in head and neck cancer models ${ }^{27,28)}$.

IL-13 has been known as a causative factor of cell apoptosis in several previous studies. Borowski et al. reported that IL-13 can be a mediator on lung epithelial cells as an apoptotic effector, which leads to loss of functional airway tissue and finally results in asthma ${ }^{29)}$.

Several studies have already reported about the role of IL-13 as a pathogen in other cells and diseases other than podocytes. Heller et al. found that IL-13 can effect on intestinal epithelial barrier dysfunction and eventually cause ulcerative colitis ${ }^{30)}$. For this explanation, signal transduc- tion qualities mediated by the respective receptors for IL13 may result in distinct patterns of transcription regulation, ultimately explaining the unique role of IL-13 in asthma pathogenesis. JAK/STAT activation pathway can be an optional mechanism to explain these results ${ }^{31}$. This pathway is induced by the IL-13 receptor complex and then eventually causes cell apoptosis and destruction of cell junctions ${ }^{31}$. Exact mechanisms of these mediators, however, are unclear.

In this study, it is implicated that IL-13 can induce podocyte apoptosis. Our results and previous studies above indicate that IL-13 can be related to extrinsic apoptosis of podocyte, blocking this signal pathway.

Our study has several limitations: First, we were unable to reveal all exact mechanism of IL-13 in podocytes. Second, we did not include treatment attempt to prevent podocyte apoptosis into our experiments. Despite these limitations, our study is the first attempt to demonstrate the IL-13 as a key marker and potential treatment target to prevent changes related to cell death in human podocytes.

In conclusion, our preliminary results suggest that IL-13 may increase podocyte apoptosis. Such alterations can be relevant to the foot process changes in podocytes related to pathogenesis of proteinuria in the IL-13-induced MCNS model. Further studies about the methods of suppression of IL-13 are needed, and it will be noteworthy to explore whether IL-13 modulation can modify podocytes from MCNS. 


\section{Conflict of interest}

The authors of the manuscript declare no conflict of interest.

\section{Role of funding source}

\author{
This research was supported by the Basic Science Research \\ Program through the National Research Foundation of \\ Korea (NRF) and funded by the Ministry of Education, \\ Science and Technology (2013R1A1A1012112 to J.I. Shin \\ and 2016R1D1A1B03931888 to T.S. Ha).
}

\section{References}

1. Churg J, Habib R, White RH. Pathology of the nephrotic syndrome in children: a report for the International Study of Kidney Disease in Children. Lancet 1970;760:1299-30.

2. Haas M, Meehan SM, Karrison TG, Spargo BH. Changing etiologies of unexplained adult nephrotic syndrome: a comparison of renal biopsy findings from 1976-1979 and 1995-1997. Am J Kidney Dis 1997;30:621.

3. Trompeter RS, Lloyd BW, Hicks J, White RH, Cameron JS. Longterm outcome for children with minimal-change nephrotic syndrome. Lancet 1985;:368-70.

4. A report of the International Study of Kidney Disease in Children. The primary nephrotic syndrome in children. Identification of patients with minimal change nephrotic syndrome from initial response to prednisone. J Pediatr 1981;98:561-4.

5. Teeninga N, Kist-van Holthe JE, van Rijswijk N, de Mos NI, Hop WC, Wetzels JF, et al. Extending prednisolone treatment does not reduce relapses in childhood nephrotic syndrome. J Am Soc Nephrol 2013; 24:149-59.

6. Tarshish P, Tobin JN, Bernstein J, Edelmann CM Jr. Prognostic significance of the early course of minimal change nephrotic syndrome: Report of the International Study of Kidney Disease in Children. J Am Soc Nephrol 1997;8:769-76.

7. Gipson DS, Chin H, Presler TP, Jennette C, Ferris ME, Massengill S, et al. Differential risk of remission and ESRD in childhood FSGS. Pediatr Nephrol 2006;21:344-9.

8. D'Agati VD. Pathologic classification of focal segmental glomerulosclerosis. Semin Nephrol 2003;23:117-34.

9. Schnaper HW. Idiopathic focal segmental glomerulosclerosis. Semin Nephrol 2003;23:183-93.

10. Pavenstadt H, Kriz W, Kretzler M. Cell biology of the glomerular podocyte. Physiol Rev 2002;83:253-307.
11. Asanuma K, Mundel P. The role of podocytes in glomerular pathobiology. Clin Exp Nephrol 2003;7:255-9.

12. McKenzie AN, Culpepper JA, de Waal Malefyt R, Briere F, Punnonen J, Aversa G, et al. Interleukin 13, a T-cell-derived cytokine that regulates human monocyte and B-cell function. Proc Natl Acad Sci USA 1993; 90:3735-40.

13. Cheung W, Wei CL, Seah CC, Jordan SC, Yap HK. Atopy, serum IgE, and interleukin-13 in steroid-responsive nephrotic syndrome. Pediatr Nephrol 2004;19:627-32.

14. Park SJ, Saleem MA, Nam JA, Ha TS, Shin Jl. Effects of interleukin13 and montelukast on the expression of zonula occludens-1 in human podocytes. Yonsei Med J 2015;56:426-32.

15. Majno G, Joris I. Apoptosis, oncosis, and necrosis. An overview of cell death. Am J Pathol 1995;146:3-15.

16. Gavrieli Y, Sherman Y, Ben-Sasson SA. Identification of pro-grammed cell death in situ via specific labeling of nuclear DNA fragmentation. J Cell Biol 1992;119:493-501.

17. Lai KW, Wei CL, Tan LK, Tan PH, Chiang GS, Lee CG, et al. Overexpression of interleukin-13 induces minimal-change-like nephropathy in rats. J Am Soc Nephrol 2007;18:1476-85.

18. Ha TS, Nam JA, Seong SB, Saleem MA, Park SJ, Shin Jl. Montelukast improves the changes of cytoskeletal and adaptor proteins of human podocytes by interleukin-13. Inflamm Res 2017;66:793802.

19. Yap HK, Cheung W, Murugasu B, Sim SK, Seah CC, Jordan SC. Th1 and Th2 cytokine mRNA profiles in childhood nephrotic synd rome: evidence for increased IL-13 mRNA expression in relapse. J Am Soc Nephrol 1999;10:529-37.

20. Kroemer G, Galluzzi L, Brenner C. Mitochondrial membrane permeabilization in cell death. Physiol Rev 2007;87:99-163.

21. Ryu M, Mulay SR, Miosge N, Gross O, Anders HJ. Tumour necrosis factor-alpha drives Alport glomerulosclerosis in mice by promoting podocyte apoptosis. J Pathol 2011;226:120-31.

22. Galluzzi L, Vitale I, Abrams JM, Alnemri ES, Baehrecke EH, Blagosklonny MV, et al. Molecular definitions of cell death subroutines: recommendations of the Nomenclature Committee on Cell Death 2012. Cell Death Differ 2012;19:107-20.

23. Faleiro L, Kobayashi R, Fearnhead H, Lazebnik Y. Multiple species of CPP32 and Mch2 are the major active caspases present inapoptotic cells. EMBO J 1997;16:2271-81.

24. Polverino AJ and Patterson SD. Selective activation of caspases during apoptotic induction in HL-60 cells. J Biol Chem 1997;272: 7013-21.

25. Zou H, Henzel WJ, Liu X, Lutschg A, Wang X. Apaf-1, a human protein homologous to C. elegans CED-4, participates in cytochrome c-dependent activation of caspase-3. Cell 1997;90:40513.

26. Manna SK, Aggarwal BB. IL-13 suppresses TNF-induced activation of nuclear factor-kappa B, activation protein-1, and apoptosis. J Immunol 1998;161:2863-72.

27. Kawakami M, Kawakami K, Puri RK. Apoptotic pathways of cell 


\section{www.chikd.org}

death induced by an interleukin-13 receptor-targeted recombinant cytotoxin in head and neck cancer cells. Cancer Immunol Immunother 2002;50:691-700.

28. Kawakami M, Kawakami K, Puri RK. Tumor regression mechanisms by IL-13 receptor-targeted cancer therapy involve apoptotic pathways. Int J Cancer 2003;103:45-52.

29. Borowski A, Kuepper M, Horn U, Knüpfer U, Zissel G, Höhne K, et al. Interleukin-13 acts as an apoptotic effector on lung epithelial cells and induces pro-fibrotic gene expression in lung fibroblasts. Clin Exp Allergy 2008;38:619-28.
30. Heller F, Fromm A, Gitter AH, Mankertz J, Schulzke JD. Epithelial apoptosis is a prominent feature of the epithelial barrier disturbance in intestinal inflammation: effect of pro-inflammatory interleukin-13 on epithelial cell function. Mucosal Immunol 2008;1 Suppl 1:S58-61.

31. Friedrich K, Brändlein S, Ehrhardt I, Krause S, Luttmann W. Interleukin-4 and Interleukin-13 receptors trigger distinct JAK/STAT activation patterns in mouse lymphocytes. Signal Transduction 2003;3:26-32. 